\title{
Elastic resistance exercises for prevention of trunk deformities - a case study D Pavlů * and D Pánek
}

\author{
Address: Charles University Prague, Dep. of Physiotherapy FTVS J. Martiho 31, Prague 6, Czech Republic, 162 52, Czech Republic \\ Email: D Pavlů* - dagmarpavlu@iol.cz \\ * Corresponding author
}

from 6th International Conference on Conservative Management of Spinal Deformities

Lyon, France. 21-23 May 2009

Published: I4 December 2009

Scoliosis 2009, 4(Suppl 2):P2 doi:I0.I |86/|748-7|6|-4-S2-P2

This abstract is available from: http://www.scoliosisjournal.com/content/4/S2/P2

(C) 2009 Pavlů and Pánek; licensee BioMed Central Ltd.

\section{Background}

Some previous studies supported the clinical effectiveness of the Brügger-concept in the treatment of idiopathic scoliosis and showed that treatment can reduce magnitudes of thoracolumbar and lumbar curves. The Brügger-Concept emphasizes self exercises, and it uses alternating concentric and eccentric contraction against elastic resistance.

\section{Objectives}

The purpose of this case study was to analyze EMG activity during "Agistic-Eccentric-Contraction-Exercises" with elastic resistance according the Brügger-Concept, with a primary focus on the trunk.

\section{Subjects and methods}

The present pilot study is a case report on a single proband. Surface EMG (Noraxon) was recorded on one healthy subject during 3 resistive exercises using TheraBand (blue color). EMG activity during the agistic-excentric-exercises was analyzed on $\mathrm{m}$. obliquus abdominis int., $\mathrm{m}$. rectus abdominis, $\mathrm{m}$. latissimus dorsi, m.erector spinae TH-L on the right and left side. The EMG activity was analyzed and compared with MVC. Results were examined by exercise for improvement of the function of trunk lateroflexion, rotation, and frontal shift of thorax, and this was documented with EMG-activity in m. latissimus dorsi $4 \% \mathrm{MVC}$ - 24\% MVC, in $\mathrm{m}$. obliqus abd. int. $6 \% \mathrm{MVC}-73 \% \mathrm{MVC}$, in $\mathrm{m}$. erector spinae Th-L $1 \% \mathrm{MVC}$ - 52\% MVC and in m. rectus abdominis 2\% MVC - 3\% MVC. During the exercises, increases and decreases in
EMG activity were seen in analyzed muscles. Detailed results will be described in the presentation.

\section{Conclusion}

This pilot study indicates the effectiveness of elastic resistance Brügger-Exercising, which was developed empirically and under support of neurophysiological regulations. Fluent, harmonic motion, provided throughout the whole range of motion, resisted by elastic bands that alternate concentric and eccentric muscle contractions with decreasing muscle activation, effects agistic-eccentric-contraction-exercises with elastic resistance in accordance with the Brügger theory. The \% of MVC that we analyzed are in conformity with general functional training requirements. The exercise that was evaluated with respect to the trunk can therefore be seen as one possibility of how to prevent trunk deformities.

\section{Acknowledgements}

The study was supported by grant from Czech Ministry of Education, Youth and Physical Education MSM 0021620864. 